\title{
Adoção de crianças público-alvo da Educação Especial: adaptação familiar e o contexto escolar
}

\author{
Carolina Terribile Teixeira* \\ Elisane Maria Rampelotto**
}

\section{Resumo}

Este estudo tem como tema central a adoção de crianças que são público-alvo da Educação Especial, e apresenta como problema de pesquisa o que leva pessoas a optar por essa modalidade de adoção e como acontece a adaptação familiar e escolar. Para isso traz como objetivo geral compreender as relaçóes sociais e humanas envolvidas no processo de adoção de crianças público-alvo da Educação Especial. E como objetivos específicos identificar o que leva pessoas a optarem por essa modalidade de adoção; descrever o processo de adaptação familiar; relacionar o processo de adoção dessas crianças com a prática da Educaçẫo Especial. A metodologia utilizada é a qualitativa, com a realização de entrevistas com pessoas que fizeram esse tipo de adoção, sendo os sujeitos identificados como F1 e F2. Como fundamentação teórica foram utilizadas leis e estatutos como, por exemplo, a Constituição Federal e o Estatuto da Criança e do Adolescente, assim como a Lei Nacional de Adoção. Além desses referenciais de cunho jurídico, também foram utilizados autores que há algum tempo se dedicam a estudar sobre a adoção, como Weber, entre outros. Os resultados demonstram a necessidade de ser uma decisão consciente e segura, pois a adoção é, sem dúvida, um ato de amor, abnegação e de muita responsabilidade. Ressalta a necessidade de buscar orientaçóes prévias e profissionais qualificados para atender às necessidades das crianças adotadas.

Palavras-chave: Educação; Educação Especial; Alteridade deficiente.

* Mestre em Educaçáo pela Universidade Federal de Santa Maria, Santa Maria, Rio Grande do Sul, Brasil.

** Professora doutora da Universidade Federal de Santa Maria, Santa Maria, Rio Grande do Sul, Brasil. 


\section{Special needs adoption: family adaptation and school context}

\section{Abstract}

This study aims at investigating the adoption of children with special needs and presents the reasons why people opt for this modality of adoption and how family adaptation takes place as research problems. The general objective of this study is to comprehend social and human relationships involved in the process of special needs adoption. The specific objectives of this study are to identify what leads people to opt for special needs adoption, to describe the process of family adaptation and to relate the process of special needs adoption with the practice of Special Needs Education. The methodology of this study is qualitative, using interviews with people who opted for special needs adoption. Laws were used as theoretical framework such as the Federal Constitution, the Child and Adolescent Statute and the National Law of Adoption as well. Apart from this theoretical framework of legal nature, authors who have been dedicating to study adoption, such as Weber, and others have been used. Results show special needs adoption as having the necessity of being a conscious and secure decision because the adoption is doubtlessly an act of love, abnegation, and great responsibility. The special needs adoption has the necessity of seeking previous orientations and qualified professionals to assist adopted children's needs.

Keywords: Education; Special Education; Alterity disabled.

\section{Introdução}

Muito se fala em adoção, seus aspectos psicológicos e jurídicos. Também muito se fala em família e sobre a importância desta estar presente na escola. Porém, pouco se fala sobre adoção de crianças público-alvo da Educação Especial e sobre as famílias que optam por essa modalidade de adoção. Menos ainda se fala nos aspectos que envolvem a Adoção dessas crianças, a Família e a Escola (NUNES; SAIA; TAVARES, 2015; WEBER, 2011; SOUZA; CASANOVA, 2011; ARPINI, 2009).

A adoção de crianças público-alvo da Educação Especial já foi abordada por meios de comunicaçáo em forma geral, porém parece que os educadores esquecem de olhar para esse viés. Principalmente os profissionais da Educação Especial, que podem fazer parte das equipes que orientam as pessoas candidatas a adotar uma criança público-alvo da Educação Especial.

Nossa atuação como professores de educação especial não fica apenas centrada na sala de recursos, classe especial ou outra; devemos estar atentos para todos os aspectos que envolvem nossos alunos, principalmente seus contextos familiares, que se refletem em sala de aula.

Nesta pesquisa é abordado como tema central a adoção de crianças que são público-alvo da Educação Especial; e, como problema de pesquisa: o que leva pessoas a optarem por essa modalidade de Adoção e como acontece a adaptaçáo familiar e escolar? 
Para delinear esta pesquisa foi traçado como objetivo geral: compreender as relações sociais e humanas envolvidas no processo de adoção de crianças público-alvo da Educação Especial. E como objetivos específicos: identificar o que leva pessoas a optar por essa modalidade de adoção; descrever o processo de adaptação familiar; relacionar o processo de adoção de crianças público-alvo da Educação Especial com a prática da Educação Especial.

As primeiras leis sobre adoção começam a surgir a partir do final do século XX e de lá para cá vêm evoluindo. Atualmente, a adoção é respaldada pela Constituição Federal de 1988 (Brasil, 1988) que, no seu artigo 227, prevê como dever da família que as crianças e adolescentes tenham assegurados direitos como saúde, educaçáo e convivência familiar. Além disso, em seu parágrafo $5^{\circ}$, afirma que a adoção será assistida pelo Poder Público em forma de Lei.

Duas leis tratam de forma mais específica da adoção, são elas: a Lei de Adoção número 12.010 de agosto de 2009 (Brasil, 2009) e o Estatuto da Criança e do Adolescente (ECA) - Lei 8.069/1990 (Brasil, 1990). No ECA fica previsto, no seu artigo 19, o direito a toda criança de crescer em uma família, sendo a sua própria ou substituta.

Nessas leis ainda estão afirmados os direitos do adotante e do adotado, quem pode adotar e ser adotado, e o que é necessário para tal. As determinaçóes das leis também visam ao bem estar do adotando e sua segurança na nova família, para que possa ser estabelecida uma boa relaçáo entre ambas as partes. Ressaltamos que o processo de adoçáo corre em segredo de justiça para preservar o menor envolvido.

A adoção de crianças que são público-alvo da Educação Especial segue os mesmos procedimentos estabelecidos pela Lei Nacional de Adoção no 12.010 de 3 de agosto de 2009. Inclusive em seu artigo 28, parágrafo $5^{\circ}$, diz que anterior à inserção da criança em família substituta, há uma preparação e acompanhamento realizados por uma equipe interprofissional. Já o artigo 87 da mesma lei prevê campanhas de estímulo ao acolhimento através da obtenção de guarda; e dentre diversas características de crianças, estáo citadas aqui as com necessidades específicas de saúde ou com deficiências.

\section{Família e escola como pontos de apoio}

A adoção de crianças público-alvo da Educação Especial, segundo Souza e Casanova (2011, p. 36), "exige muita preparaçáo dos futuros pais e familiares, e os fatos demonstram que há uma surpreendente mudança nestas crianças após receberem o carinho familiar". O fato de passar a receber atenção e estímulos faz muita diferença no comportamento e desenvolvimento de qualquer criança.

Com a melhor compreensão das necessidades dessas crianças, tanto a família quanto a escola são pontos de apoio uma à outra na busca por realizar um trabalho que estimule o seu desenvolvimento e para que sejam respeitadas e realmente incluídas em seus núcleos familiares e na sociedade em que vivem. Por isso, o trabalho dos profissionais da educaçáo, como da Educaçáo Especial, especificamente, com a famí- 
lia é de suma importância. Com esse apoio e troca de conhecimentos e experiências poderão descobrir qual caminho seguir na educação de cada criança, respeitando sua individualidade.

O profissional da área da Educação Especial pode auxiliar as pessoas que pretendem adotar uma criança público-alvo da Educação Especial, conversando sobre as características dessa criança, mostrando fatos que podem ou não acontecer em decorrência da alteridade ${ }^{1}$ deficiente. Também, pode aconselhar a família a respeito de aspectos educacionais e procedimentos que podem ser tomados, como a procura de outros profissionais como fonoaudiólogos, fisioterapeutas, psicólogos, entre outros, conforme a necessidade da criança e da família.

No ambiente escolar é importante que os pais relatem a história de vida da criança, pois fatos vividos anteriormente à adoção provavelmente poderáo ser refletidos em seu comportamento, através de aspectos psicológicos como insegurança ou agressividade, por exemplo. Dessa forma, acontecendo uma troca de informaçóes entre pais e professores, poderá se visualizar melhor o que é necessário para o atendimento dessa criança e para que ela tenha um bom desenvolvimento e aprendizagem. Também se pode evitar constrangimentos em atividades escolares.

É preciso refletir que a questáo de ter passado por uma adoção é parte da história social da criança e a escola precisa saber das histórias sociais de seus alunos. [...]. Ao mesmo tempo em que relatam a questão, os pais podem perguntar que tipo de atividades relacionadas com nascimento, genética e infância são solicitadas aos alunos. (WEBER, 2011, p.131).

A escola e seus professores, por sua vez, devem estar preparados para lidar com as diferenças, além das que incluem o sujeito com necessidade especial, mas também para as diferenças na forma de constituição das famílias.

\section{Percurso metodológico}

O presente artigo tem a pesquisa qualitativa como método específico, pois essa metodologia proporciona o espaço necessário para pesquisar em educação, transitando por outras áreas que envolvem as relaçóes humanas, as ciências sociais, como por exemplo, o direito e a psicologia. Para isso recorremos à leituras/estudos com a finalidade de obter conhecimento para debater sobre assuntos abordados que são de áreas não diretamente correspondentes à da educação.

Além disso, a pesquisa apresentada é um estudo de caso a respeito das experiências das famílias participantes. É um estudo de caso a partir do entendimento de que este se caracteriza "do desejo de entender os fenômenos sociais complexos" (YIN, 2010, p. 24).

Para coletar as informaçôes necessárias para o estudo foi realizada uma entrevista com pessoas que fizeram a opção pela adoçáo de crianças público-alvo da Educação Especial. A entrevista é composta por oito perguntas diversas e a oitava está subdividida em quatro itens, que estáo voltadas para questôes específicas do ambiente 
escolar. Com essas perguntas visa-se compreender a situação vivida por essas pessoas, suas atitudes e comportamentos.

O método da entrevista para a coleta de dados foi escolhida porque através dela pode ser oportunizada uma conversa entre pesquisador e o sujeito pesquisado, gerando uma troca de conhecimentos e a compreensão do outro. Pois, "se for considerada como apenas uma técnica eficiente para obter respostas pré-pautadas por um questionário, a entrevista não promoverá a comunicação entre pessoas" (CAPUTO, 2003 apud RAMPELOTTO, 2004, p.41).

Antes de chegar aos sujeitos da pesquisa foi necessário buscar informações em escolas especiais e inclusivas do município de Santa Maria. Essas indicaram pessoas que se encaixavam no propósito da pesquisa e poderiam estar disponíveis para participar e contar suas histórias.

Após o contato inicial com as escolas, foi realizado o primeiro contato com os sujeitos da pesquisa e o convite para participar da mesma. Sendo assim, foram contatadas as famílias. Seguinte ao aceite, todos assinaram o termo de consentimento livre e esclarecido de participação na pesquisa. Os sujeitos serão identificados por $\mathrm{F}$ (de família) e um número, ficando disposto da seguinte maneira: F1, F2.

Caracterização das famílias:

F1 - casal e três filhos adotados, residentes em Santa Maria, sendo que ambos participaram da entrevista. A primeira adoção foi realizada há cerca de trinta anos, no início sabiam que a menina é autista e, após a adoção, descobriram que a menina também é surda. A segunda adoçáo aconteceu cerca de dez anos depois da primeira, de um menino que aparentemente náo tinha deficiência, mas que apresentou um atraso no desenvolvimento, e as características intensificaram-se no período escolar, sendo diagnosticado com déficit cognitivo. A terceira adoção foi realizada poucos anos depois da segunda, de uma menina sem deficiência que apresentou dificuldades de aprendizagem na escola.

F2 - casal e quatro filhos (três biológicos do primeiro casamento da esposa e um adotado pelo casal), residentes em uma cidade próxima a Santa Maria, sendo que apenas a esposa concedeu entrevista. A adoção aconteceu alguns anos após o casamento; o casal queria um filho, mas a esposa só poderia engravidar através de inseminação e também não queria um bebê. Como ela trabalha na casa de passagem de sua cidade, conheceu o menino que é surdo, percebeu a necessidade que ele tinha de ter uma família e fez a proposta de adotá-lo ao esposo, que concordou. A adoção aconteceu à cerca de dois anos.

\section{Resultados e discussão}

Os resultados alcançados foram de grande valia, portanto, pretende-se realizar uma reflexão a respeito das informaçóes obtidas no desenvolvimento da pesquisa. Para isso, são utilizados excertos das entrevistas realizadas com as famílias que fizeram a adoçãoo de crianças público-alvo da Educação Especial. 
Com a pesquisa e o contato com as famílias, foi possível perceber que o ato da adoção de crianças público-alvo da Educação Especial não é algo recente ou de moda, mas que, sim, está presente em famílias com características diferenciadas e com histórias e tempos diferentes. Ela está presente desde quando as pessoas que são reconhecidas como público-alvo da Educação Especial começavam a conquistar mais espaço na sociedade e continua até hoje, quando contam com seus direitos garantidos nas políticas sociais.

A discussão acontecerá seguindo a ordem das perguntas realizadas na entrevista e as respectivas respostas obtidas. Após, serão discutidos outros pontos levantados pelos entrevistados no decorrer da conversa.

Através das entrevistas ficou explícito que são motivos variados que levam as pessoas a optar por essa modalidade de adoção. Também, que às vezes essas pessoas nem pensavam na possibilidade de adoção e o que fez despertar esse desejo foi o envolvimento com a criança. Essas motivaçôes também são apresentadas por Weber (2011) que também elucida:

Desenvolver motivação para adoções especiais, crianças [...], com necessidades especiais: [...]. Ao ouvir casos sobre adoção e compreender que crianças têm prioridade e é um direito da criança de viver em família, é possível desenvolver também em alguns adotantes um lado altruísta que as leve a adotar crianças diferentes do perfil idealizado. (WEBER, 2011, p. 37)

Essa característica está presente nos dois casos analisados.

Eu encontrei ela primeiro, que eu tinha uma prima minha que trazia crianças para passar o final de semana. E aí eu comecei também, [...] trazia todo final de semana a $\mathrm{AN}$ e outra [refere-se a outra criança da casa de adoçáo], a outra mudava, mas a AN ficava. (F1)

Eu conheci o JE na casa de passagem quando eu fui trabalhar lá em 2009. Quando eu cheguei na casa ele já estava [...] quando eu cheguei lá eu já soube que ele era surdo e que a mãe não aparecia. (F2)

A primeira questão diz o seguinte: $\mathrm{O}$ que levou você(s) a optar(em) pela adoção de uma criança que faz parte do público-alvo da Educação Especial? - Nas respostas a seguir percebe-se o grande envolvimento emocional das pessoas, mesmo sendo uma atitude pensada, bastante consciente. Há um impulso afetivo e uma relação de carinho muito grande entre adotantes e adotados.

Aí nós fomos visitar a família dela e quando nós vimos aquela situação e nós voltamos eu disse [...] eu to preparado, se tu quiser vamos adotar [...]. (F1)

O nosso coração só dizia que era para adotar. (F1)

Foi por a gente realmente querer um filho e eu náo querer uma criança pequenininha, não querer um bebê. E senti a necessidade que ele tinha de ter uma família. Foi uma coisa assim....acho que mais espiritual. E esse amor foi nascendo entre nós. [...] Várias coisas me motivaram a adotar ele. (F2) 
Outro fato que pode ser destacado é que F2 não pensou apenas na vontade que tinha de adotar, mas pensou também na posição da criança e naquilo que ele precisava. Além disso, é uma adoção duplamente diferenciada, rompendo com o padrão comum das adoçôes, pois além de ter adotado um menino surdo, foi uma adoção tardia, uma vez que a criança já estava com sete anos. Nesses casos de adoção há dificuldades em conseguir adotantes para essas crianças e F2 rompeu com os preconceitos ali enraizados.

Em uma declaração F2 deixa explícita a primeira impressão que teve da criança que viria a ser seu filho. E que de alguma forma contribuiu para a realização da adoção.

Quando eu cheguei na casa a minha primeira sensaçấo foi de es-
tranhar ele [...]. Ele era uma criança bem feinha, com os dentes
todos estragados, todos cariados. E eu não sabia como lidar com
ele porque realmente a primeira impressão que eu tive assim dele,
foi de repulsa [...]. Com o passar do tempo foi passando [...] e fui
interagindo com as crianças da casa e com ele. [...] Com o passar
do tempo eu fui me apegando ao JE algumas coisas foram me
incomodando, de algumasa atitudes na casa que tinham em relação
a ele, de nâo dar importância a ele. (F2)

A segunda e a terceira perguntas são referentes às orientaçóes buscadas pelas famílias. F1 buscou orientaçôes anteriores à decisão pela adoção; já F2 recorreu a profissionais após a adoção. Sendo que o filho de F2, quando morava na casa de passagem, recebia atendimento da educadora especial na escola e depois quando adotado passou a frequentar a APAE (Associação de Pais e Amigos dos Excepcionais). Souza e Casanova (2011) alertam para a preparação dos futuros pais em relação às necessidades das crianças, sendo que esse comportamento foi observado nos pais que participaram da pesquisa.

Percebe-se a preocupação com o bem estar familiar e da criança; a busca por orientaçóes, como no caso de F1, foi muito importante para que decidissem com consciência do passo que estavam dando em suas vidas. Em entrevista, comentaram o que pensavam antes da decisão:

Temos que ter uma condição realmente de adotá-la e saber que ela é diferenciada. (F1)

E para corresponder à necessidade de sanar as dúvidas a respeito da condição da criança que pretendiam adotar, é que procuraram orientaçôes médicas.

Nós fomos no Dr. DE e nós visitamos outros médicos [...]. Daí ele nos disse assim, olha: vocês podem ter filhos normais, podem ter filhos deficientes [...] e colocou várias condiçôes. E vocês estão escolhendo uma filha deficiente. Então, vocês estão escolhendo o que no bolo seria o pior, mas é uma consciência que vocês têm que ter de que é isso o que vocês querem. (F1)

Esse contato médico nem sempre é bem correspondido, o primeiro consultado colocou várias possibilidades a eles e mostrou a necessidade de ser uma decisão bem 
pensada. Já ao procurar outros médicos, F1 não foi bem compreendida e também foi repreendida pela sua intenção em realizar a adoção de uma criança público-alvo da Educação Especial.

Assim ó, veio um médico disse assim, que não era uma criança, era um monstro. Que para manter um tratamento era caríssimo, que era só nos Estados Unidos. Até me lembro assim porque foi um dos dias mais infeliz de ele me dizer aquilo né. [...]. Na realidade ele fez o papel dele, foi realista né. (F1)

Quando nós fomos falar, na época ela tava sendo atendida pelo Dr. CL e ele achou um absurdo a gente adotar uma criança e ele disse: Bah isso vai ser complicado para vocês, aí ele me mandou conversar com a psicóloga. (F1)

Outro fator abordado por F1 durante a entrevista foi o fato de outras famílias terem se interessado pela adoção da criança, mas ao identificarem que ela era uma menina com deficiência, desistiam. Esse é um comportamento bastante comum, pois geralmente as pessoas que vão em busca da adoção procuram uma criança idealizada. E F1 comenta o que acontecia com sua filha quando estava no lar à espera por ser adotada.

As famílias levavam para os médicos e as famílias desistiam. (F1)

F1 também salienta que muitas pessoas a procuram para ter uma orientação a respeito da adoção, já que tem experiência, pois seus três filhos são adotados e diz:

Uma coisa assim que me deixa bem claro hoje, que uma pessoa que quer adotar [...] ela não pode ter escolha. Se a pessoa me diz assim: ah eu queria adotar uma criança loirinha de olhos azuis [...] eu acho que essa pessoa não tá em condiçôes de adotar porque se tu tiver um teu, tu não ia escolher ele, ia ser aquele que nascesse. (F1)

Algumas vezes a família, por mais que tenha procurado estar preparada ao realizar a adoçáo de crianças público-alvo da Educaçáo Especial, atravessa alguns problemas ocasionados pela frustração na demora de resultados positivos no desenvolvimento da criança. Situação que também foi salientada na entrevista de F1.

Não foi fácil, [...]. Dez anos correndo atrás, fazendo de tudo o que tu possa imaginar, psicólogo, hidroterapia. Eu sofri uma decepção porque eu tinha certeza que ia conseguir. E outra, quando estávamos há seis meses com ela [...] e aí foi constatado também que além de autista ela é surda. (F1)

Já F2, que tinha conhecimento dos atendimentos recebidos pela criança enquanto estava na casa de passagem, deu seguimento ao atendimento com a educadora especial e incluiu o atendimento com fonoaudióloga. Somente um ano depois procurou a Escola de Surdos.

Os especialistas que a gente procurou foi sempre a fono e a educadora especial né. (F2) 
A quarta e a quinta pergunta dizem respeito à reação das pessoas mais próximas e a adaptação familiar. Algumas famílias têm medo da adoção, pois temem que no futuro os filhos adotados gerem situaçóes constrangedoras ou reneguem a família adotiva para ir em busca da família biológica. Sabe-se que essas situações não são regras, podem acontecer, como também podem não acontecer. Porém, o medo torna-se maior quando se trata de uma adoção de criança público-alvo da Educação Especial, pois a família vai precisar se reorganizar para atender todas as necessidades específicas dessa criança.

Neste sentido, é valido ressaltar que:

A chegada de um filho por adoção será alvo de curiosidade e comentários. Ele terá que entrar numa família já constituída. Há familiares que aceitam o fato muito bem, enquanto outros questionam. [...] Esta família extensa também precisa estar ciente e preparada para a chegada deste novo membro. (SOUZA, CASANOVA, 2011, p. 144).

Nos casos analisados, cada família reagiu de uma forma. Já quanto à adaptação das crianças não tiveram dificuldades, pois F1 e F2 já tinham certa convivência com as crianças. Nesse sentido, o obstáculo maior realmente foi a opinião de parentes e amigos.

Ficaram espantados por não ter conhecimento [...], mas ninguém foi contra. (F1)

E quando nós decidimos adotar essa criança [...]. E é uma criança especial, uma criança que requer um atendimento diferenciado. $\mathrm{E}$ aí nós decidimos. Vamos adotar? Vamos! Sentamos nós dois, conversamos e aí sentamos com os filhos. [...]. A família dele [esposo da entrevistada] aceitou melhor do que a minha. (F2)

Quando questionados sobre se os filhos sabem que são adotados, que é a sexta pergunta, todos respondem que sim. Na F2, o menino tem consciência da adoção por ter vivido com sua mãe biológica até mais ou menos os quatro anos de idade, depois ter vivido na casa de passagem, para somente após ser adotado. Já no caso de $\mathrm{F} 1$, consideram que os filhos entendem à maneira deles mesmos, por exemplo, como filhos do coração.

Quanto à questão de número sete, que é sobre a relação entre pais e filhos, todos garantem que se relacionam muito bem. A esse respeito, destacamos a afirmação de Weber quando diz:

Uma relação de amor entre pais e filhos também é uma relação construída, e isso ocorre tanto com pais e filhos biológicos quanto com pais e filhos adotivos. Esta relação de filiação, como qualquer outra relação de amor, sempre é um processo, ela é dinâmica e não pode parar nunca. (WEBER, 2011, p. 31).

Os participantes da pesquisa afirmam que são companheiros de seus filhos, procuram estar presentes em suas atividades e ser participativos, além de grandes incentivadores. 
As questôes referentes ao ambiente escolar foram abordadas na pergunta número oito (que foi subdividida). Destaca-se que a relaçáo família-escola que acontece de forma harmoniosa contribui para o desenvolvimento da criança, segundo Sigolo e Oliveira (2008, p. 165) "[...] a criança no seu desenvolvimento partilha das influências destes dois contextos durante parte significativa da sua vida"

Sobre os aspectos referentes ao ambiente escolar foi salientado pelos entrevistados a importância do atendimento da educação especial, assim como anteriormente de outros profissionais. Neste viés, Campos (2009) considera que a inclusão não se trata de apenas integrar as crianças com deficiência na escola, mas sim conquistar seu espaço junto a ela.

Com a realização da pesquisa foi possível perceber que todos são bastante participativos e presentes nas escolas de seus filhos. A F1 ressaltou a dificuldade que teve para encontrar uma escola que aceitasse sua filha, até que uma escola especial aceitou atendê-la, mesmo sem ter profissionais habilitados para a múltipla deficiência da criança.

Na época lecionavam lá no CI [escola pública de Santa Maria] aula para surdos e não aceitavam ela porque ela é autista. Lá no BI [escola pública de Santa Maria] tinha aula para autistas, mas não aceitavam ela porque ela é surda. (F1)

F2 comentou a importância da orientação da Educadora Especial para que procurasse a Escola de Surdos em Santa Maria a fim de que seu filho convivesse com a comunidade surda e pudesse se desenvolver plenamente.

A Educadora Especial do município disse que ele deveria vir para a Escola [de surdos] porque ela conhecia, para ele desenvolver as habilidades dele. (F2)

Também ressaltou a importância que a Escola de Surdos está tendo na aprendizagem de seu filho, além de sua boa relação com o ambiente escolar.

Ele foi aprender LIBRAS [Língua Brasileira de Sinais] só aqui [refere-se à escola em que JE estuda - Escola de Surdos] [...] Coisas que ele não tinha noção, ele aprendeu aqui. E aí eu vi que aqui é a escola que ele tem que estudar. (F2)

A gente é bem acolhida pelas professoras, pelo diretor. [...] Eu sempre fui uma mãe muito participativa. (F2)

Durante as entrevistas foram abordados outros fatores como, por exemplo, a preocupação em relação a outros pretendentes à adoçáo, se realmente estão conscientes do desafio. Consciência essa que está presente nos dois casos analisados e que, particularmente, não falta para F2, que declarou:

Se eu tivesse condições financeiras, eu tinha adotado mais outra guriazinha lá da casa que tem PC [paralisia cerebral]. (F2)

Essa declaraçáo explicita muito mais do que a simples vontade de adotar uma criança, ela demonstra o desprendimento, o amor e a preocupação para com a criança 
e suas necessidades. É um exemplo de forma de pensar para uma pessoa que pretende adotar, pois anterior ao desejo pessoal, é preciso analisar as possibilidades reais para isso, preparo não apenas financeiro, mas também emocional.

É oportuno enfatizarmos que a adoção não é apenas um ato altruísta, mas que precisa estar envolvida pelo desejo de constituir uma família com filhos. A partir das regulamentações sobre a adoção no ECA (BRASIL, 1990) a compreensão sobre adoçâo passa a ter outro patamar, como é comentado por Silva e Arpini (2012, p. 5253) "a adoção deixa de ser compreendida como a retirada de crianças de instituiçóes com o intuito de dar-lhes uma vida melhor, o que, muitas vezes, demonstra desejos altruístas dos adultos, para concretizar o direito de pais e filhos constituírem família”.

Por isso, é preciso que os candidatos adotantes estejam conscientes de que, além de enfrentar desafios no que diz respeito às necessidades da criança, também, há casos, que os pais precisam abrir mão de outros desejos para cumprir com o seu dever e responsabilidade.

\section{Considerações finais}

Com a realização desta pesquisa, foi possível a aproximação a uma realidade familiar diferenciada. A vontade de investigar algo diferente do que geralmente é estudado na área da Educaçáo Especial, foi um estímulo potente para a realização desta pesquisa.

A partir dos relatos das experiências vividas percebeu-se que essas pessoas doam-se aos filhos e o que os levou ao ato da adoção foi realmente o afeto, o amor e que isso possibilitou que não vissem apenas a sua própria vontade de ter ou não um filho, mas que enxergassem a necessidade dessas crianças de terem um lar, uma família, alguém que as ame, dê carinho, cuide e lute por/com elas.

Realizando uma reflexão a respeito dos objetivos delineados para esta pesquisa, percebemos que compreendemos as relaçóes sociais e humanas envolvidas no processo de adoçáo de crianças público-alvo da Educação Especial. Foi possível observá-las durante as entrevistas e perceber como as famílias adotantes reagem a esse processo. Isso levou ao alcance dos demais objetivos traçados.

Os resultados demonstram a necessidade de ser uma decisão consciente e segura, pois a adoção é, sem dúvida, um ato de amor, abnegação e muita responsabilidade. Ressalta-se a necessidade de buscar orientaçóes prévias e profissionais qualificados para atender as necessidades das crianças adotadas. Assim como, o incentivo a realização de mais pesquisas e estudos sobre o tema que ainda são escassos.

\section{Referências}

ARPINI, D. M. (Org.). Psicologia, família e instituição. Santa Maria: Ed. Da UFSM, 2009.

BRASIL. Constituiçáo da República Federativa do Brasil de 1988. Disponível em: <http://www.planalto.gov. br/ccivil_03/Constituicao/Constituicao.htm >. Acesso em: 17 out. 2012.

Estatuto da Criança e do Adolescente no Brasil. Disponível em: <http://www.planalto.gov.br/ccivil_03/LEIS/L8069.htm>. Acesso em: 17 out. 2012. 
BRASIL. Lei da Adoçâo. Disponível em: <http://www.planalto.gov.br/ccivil_03/_Ato2007-2010/2009/Lei/ L12010.htm>. Acesso em: 17 out. 2012.

CAMPOS, C. A. Esperanças equilibristas: a inclusão de pais de filhos com deficiência. Curitiba: Juruá, 2009.

CAPUTO, S. G. A escola e os terreiros. Projeto de Tese de Doutorado em Educação. Rio de Janeiro: Programa de Pós-Graduação em Educação, Pontifícia Universidade Católica do Rio de Janeiro, 2003.

NUNES, S. S.; SAIA, A. L.; TAVARES, R. E. Educação Inclusiva: entre a história, os preconceitos, a escola e a família. In: Psicologia: ciência e profissão. out./dez., 2015, vol. 35, n. 4, p. 1106 - 1119. Disponível em: <http:// www.scielo.br/scielo.php?script=sci_arttext\&pid=S1414-98932015000401106\&lng=pt\&nrm=iso\&tlng=en>. Acesso em: 02 set. 2016.

RAMPELOTTO, E. M. Mesmidade ouvinte \& Alteridade Surda: invençóes do outro surdo no Curso de Educaçáo Especial da Universidade Federal de Santa Maria. (Tese de Doutorado). Programa de Pós-Graduação em Educação, Universidade Federal do Rio Grande do Sul. Porto Alegre, 2004.

SIGOLO, S. R. R. L.; OLIVEIRA, A. M. L. A. Relação Família-Escola e o Processo de Inclusão Escolar - Subsídios para Orientação Familiar. In: MENDES, E. G.; ALMEIDA, M. A.; HAYASHI, M. C. P. I. (Org.). Temas em educaçáo especial: conhecimentos para fundamentar a prática. Brasília, DF: CAPES - PROESP, 2008.

SILVA, M. L. ARPINI, D. M. Fortificando laços e desatando nós: a adoção ao longo da história. In: ARPINI, D. M.; SIQUEIRA, A. C. (Org.) Psicologia, famílias e leis: desafios à realidade brasileira. Santa Maria: Ed UFSM, 2012.

SOUZA, H. P. ; CASANOVA, R. P. S. Adoção: o amor faz o mundo girar mais rápido. Curitiba: Juruá, 2011. WEBER, L. N. D. Adote com carinho: um manual sobre aspectos essenciais da adoção. Curitiba: Juruá, 2011.

YIN, R. K. Estudo de caso: planejamento e métodos. Tradução Ana Thorell, 4 ed. Porto Alegre: Bookman, 2010.

\section{Notas}

1 "A condiçấo daquilo que é diferente de mim; a condição de ser outro" (SILVA, 2000, p.16 apud RAMPELOTTO, 2004, p. 14)

\section{Correspondência}

Carolina Terribile Teixeira - Rua Dr. Luiz Mallo, no 58 - Bairro Itararé, CEP: 97045-520. Santa Maria, Rio Grande do Sul, Brasil.

E-mail: carol_terribile@hotmail.com - elisane2007@gmail.com

Recebido em 09 de março de 2015

Aprovado em 20 de dezembro de 2016 